\title{
Construção discursiva do ethos da autoridade institucional: poder, vigilância e revoltas escravas na Bahia
}

\author{
Discursive construction of the ethos of institutional authority: \\ power, vigilance and slave revolts in Bahia \\ Construcción discursiva del ethos de la autoridad institucional: \\ poder, vigilancia y revueltas de esclavos en Bahía \\ Eliana Correia Brandão Gonçalves $\odot$ \\ Universidade Federal da Bahia, Salvador, BA, Brasil.
}

$\diamond$

\begin{abstract}
RESUMO
O artigo tem o objetivo apresentar reflexões sobre o ethos discursivo da autoridade institucional do Império e da Província contra as revoltas encabeçadas por escravizados, como enfrentamento das condições aterrorizantes da escravidão. Para tanto, o ethos é analisado a partir do discurso da administração da Bahia no século XIX, considerando-se o texto histórico, com a finalidade de observar como o sujeito enunciador se articula com outros discursos, a partir da relação dialética entre identidade e alteridade. Os discursos oficiais são mediados pelos Oficiais da Secretaria do Governo da Bahia, enunciadores do discurso político do poder institucional, e materializados em Resolução da administração pública. Nesse viés, o ethos discursivo é um olhar sobre a cena. O leitor é convidado a participar do reconhecimento desse estado de vigilância para as revoltas escravas, que eram consideradas um problema de segurança.
\end{abstract}

Palavras-chave: Ethos discursivo. Autoridade institucional. Revoltas escravas. Bahia. Filologia.

\begin{abstract}
The article aims to present reflections on the discursive ethos of the institutional authority of the Empire and the Province against rebellions headed by slaves as a confrontation with the terrifying conditions of slavery. For that, the ethos is analyzed from the discourse of the administration of Bahia in the nineteenth century, considering the historical text, with the purpose of observing how the subject enunciator articulates with other discourses, from the dialectic relation between identity and otherness. The official speeches are mediated by the Officials of the Secretariat of the Government of Bahia, enunciators of the political discourse of institutional power, and materialized in Resolution of the public administration. In this bias, the discursive ethos is a look at the scene. The reader is invited to participate in the recognition of this state of vigilance for the slave revolts, which were considered a security problem.
\end{abstract}

Keywords: Discursive ethos. Institutional authority. Slave revolts. Bahia. Philology.

\section{RESUMEN}

El artículo tiene como objetivo presentar reflexiones sobre el espíritu discursivo de la autoridad institucional del Imperio y de la Provincia contra las revueltas dirigidas por esclavos, como confrontación de las terribles condiciones de la esclavitud. Con este fin, se analiza el ethos desde el discurso de la administración de Bahía en el siglo XIX, considerando el texto histórico, para observar cómo el sujeto enunciador se articula con otros discursos, desde la relación dialéctica entre identidad y alteridad. Los discursos oficiales están mediados por los funcionarios de la Secretaría del Gobierno de Bahía, enunciadores del discurso político del poder institucional, y se materializan en la Resolución de la Administración Pública. En este sesgo, el ethos discursivo es una mirada a la escena. Se invita al lector a participar en el reconocimiento de este estado de vigilancia para las revueltas de esclavos, que se consideraron un problema de seguridad.

Palabras clave: Ethos discursivo. Autoridad institucional. Revueltas de esclavos. Bahia. Filología. 


\section{Palavras iniciais}

Este artigo tem por objetivo analisar o ethos dis cursivo da autoridade institucional do Império e da Província contra as rebeliões encabeçadas pelos escravizados, como forma de enfrentamento das condições aterrorizantes da escravidão, considerando-se como ponto a edição filológica elaborada por Gonçalves (2018) da Resolução do Conselho Interino do Governo da Bahia de 28 de novembro de 1822, assinada pelo Oficial Maior da Secretaria do Governo da Província da Bahia, José Albino Pereira. Esse texto, produzido no contexto do século XIX, faz parte do acervo de Manuscritos da Biblioteca Nacional, no Rio de Janeiro e apresenta datação tópica de Cachoeira, Bahia.

A proposta de analisar a constituição do ethos discursivo em documentos da administração imperial e provincial é resultante de um trabalho de investigação vinculado ao projeto $^{1}$ que tem por objetivo realizar o mapeamento, a leitura, a edição e o estudo filológico, linguístico e crítico-discursivo de textos do século XVI o $\mathrm{XX}$, que registram narrativas das memórias de violências contra a população negra e contra a mulher, em suas variadas formas e discursos, disponibilizados em acervos de instituições de guarda, entre as quais a Fundação Biblioteca Nacional, o Arquivo Público do Estado da Bahia, o Arquivo Histórico Municipal de Salvador, o Arquivo Histórico Ultramarino de Lisboa e a Biblioteca Nacional da Torre do Tombo de Portugal.

Portanto, com base em corpus de análise arquivística, a saber textos institucionais, enfatiza-se a questão dos percursos de diferentes discursos, que circularam na sociedade baiana, por meio de edições filológicas de documentos do português escrito datados entre o século XVI ao XX, estabelecendo um diálogo entre a Filologia e a Análise do Discurso de linha francesa, reavaliando e reconfigurando a noção de ethos.

Nesse contexto interpretativo, a partir do corpus mobilizado, recorre-se inicialmente aos procedimentos críticos e metodológicos da Filologia, compreendendo cada produção manuscrita como a materialização do discurso das instituições, promovendo a mediação multidisciplinar, entre as diversas abordagens filológicas e as abordagens discursivas e sócio-históricas. Para Gonçalves (2017),

[...] no contexto arqueológico da Filologia, desde as suas origens, a atividade filológica [...] considerou

\footnotetext{
1 O projeto de pesquisa "Memórias de violências e (re)existências: edição e estudo linguístico" é coordenado e desenvolvido por mim no Instituto de Letras da Universidade Federal da Bahia e está vinculado ao Grupo de Estudos Filológicos e Lexicais - GEFILL. Disponível em: www.gefill. ufba.br. Acesso em: 30 set. 2019. Rede social Instagram, disponível em: https://www.picbear.org/user/ge.fil.1. Acesso em: 5 out. 2019.
}

as diversas materialidades e inscrições, sua relação visceral com a cultura e sua vinculação com a língua, a história e o tempo. O [...] filólogo articula, através do seu labor crítico, as atividades de reconfiguração dos fragmentos das histórias sociais, linguísticas e discursivas e de composição de produções editoriais (GONÇALVES, 2017, p. 199).

$\mathrm{Na}$ análise do ethos discursivo da autoridade institucional, a partir do arquivo constituído da Resolução de 1822, foi levado em consideração o contexto de enunciação do documento oficial e de seu enunciador, o Oficial Maior da Secretaria do Governo da Província da Bahia, José Albino Pereira, que emite o seu discurso em nome de Sua Majestade Imperial e Constitucional o Senhor Dom Pedro Primeiro Imperador e Defensor Perpétuo do Brasil ${ }^{2}$.

Para tal propósito, as reflexões aqui apresentadas tomaram por base os estudos desenvolvidos por Maingueneau $(2005,2006,2008)$ e Charaudeau e Maingueneau (2014), que analisam o ethos como a imagem do enunciador construída no discurso de forma interativa e articulada com os sujeitos e os discursos, e as discussões de Amossy $(2005 ; 2010)$, que interpreta a configuração do ethos como uma imagem de si no discurso, mesclando nuances sociais e identitárias. Nesse viés, compreende-se que o ethos se constitui, na Resolução, a partir de uma concepção de um discurso para o qual os conteúdos não estão dissociados da cena de enunciação, na qual o interlocutor incorpora o discurso em um contexto de representações políticas, sociais e culturais.

\section{Considerações sobre o corpus da pesquisa}

É interessante notar que o século XIX foi marcado pela prosperidade dos engenhos de cana-de-açúcar do Recôncavo e pela exportação e importação de povos escravizados da África. Diante desse e de outros problemas, é esperado que ocorram sublevações de escravos na Bahia (REIS, 1992). Assim, o ethos da autoridade institucional circulou em uma situação delicada, na qual a Bahia e o Brasil já anunciavam o fracasso da política escravista. Diante desse conflito e desafio, o ethos enuncia, no texto, uma lista de ações e providências necessárias, por meio de palavras de repressão e de ordem para evitar a possível sublevação de escravos, que poderia ocorrer em Cachoeira, cidade do Recôncavo baiano, no início do século XIX.

\footnotetext{
2 Lembramos que em 7 de setembro de 1822, o príncipe regente D. Pedro de Alcântara proclama a separação do Brasil do Reino de Portugal, no Sítio do Ipiranga, província de São Paulo e, posteriormente, em 12 de outubro de 1822 ocorreu, em sessão solene, no Senado da Câmara da cidade do Rio de Janeiro, a aclamação do "Senhor D. Pedro Imperador Constitucional do Brasil e seu Perpétuo Defensor".
} 
Em outros períodos que antecedem o ano em que a Resolução foi escrita, 1822, a Bahia já tinha registrado algumas rebeliões. Diante das conspirações e rebeliões, que ainda estavam em curso, como as ocorridas em várias cidades do Recôncavo baiano (DANTAS, 2011), o governo redobrava a vigilância e adotava medidas repressivas e punitivas, em especial, em Cachoeira, enviando tropas de Salvador, na tentativa de manter a ordem e conter os movimentos insurgentes, promovendo também perseguições e punições extremas, por parte das milícias locais (GONÇALVES, 2018).

Sabemos que o ethos está presente nos textos escritos, conforme Maingueneau,

[...] o texto escrito possui [...] um tom que dá autoridade ao que é dito. Esse tom permite ao leitor construir uma representação do corpo do enunciador (e não, evidentemente, do corpo do autor efetivo). A leitura faz, então, emergir uma instância subjetiva que desempenha o papel de fiador do que é dito (MAINGUENEAU, 2001, p. 98).

E, se o documento escrito registra as marcas, as narrativas da cena, é preciso atentar para a existência de diversas concepções de discurso e a diversidade de fins, que indicam metodologias variadas na análise discursiva da documentação histórica. Para tanto, o estudo prioriza a análise da constituição do ethos e da construção das imagens criadas no texto e nas suas interlocuções correspondentes e a situação e os recursos enunciativos observados na Resolução "quanto ao uso dos mecanismos explícito/implícito e tematizado/projetado usados na constituição dos ethé se estendem também para os conceitos de enunciado/enunciação" (HABIB, 2008 , p. 15). Vale ressaltar que a Resolução é um ato administrativo normalmente expedido pelas autoridades do executivo ou pelos presidentes de tribunais, órgãos legislativos e colegiados administrativos, para disciplinar matéria de sua competência específica, normalmente registrando uma decisão ou ordem derivada de um contexto ou de determinadas demandas sociais. "O ato está fundado na própria atribuição conferida ao órgão ou representante" (BELLOTTO, 2002, p. 87).

Como se verá adiante, foi adotada a edição semidiplomática proposta por Gonçalves (2018) da Resolução (1822), escrita em um fólio, recto e verso, reiterando a importância de edições que mantenham as características do texto. No entanto, para fins de análise, será utilizado, como corpus, excertos do manuscrito, que serão apresentados em linguagem atualizada, com o fim de facilitar a leitura e a discussão do texto, indicando-se entre parênteses, após o fragmento do texto, a indicação do fólio e da linha do manuscrito.

A seguir, serão apresentados os fac-símiles, reprodução mecânica do documento, visto que o objetivo da pesquisa é utilizar as fontes escritas como corpora para um público especializado, seguida da edição semidiplomática do texto, que apresenta a "intenção de, tendo por públicoalvo o especialista, promover um grau baixo de mediação entre a edição e o manuscrito, procurando-se preservar o máximo possível as características do documento" (ANDRADE; SANTIAGO-ALMEIDA; BARONAS, 2014, p. 38).

Figura 1 - Fac-símile e edição semidiplomática da Resolução do Conselho Interino do Governo da Bahia - 28 de novembro de 1822 - Cachoeira - Bahia - f. 1r.

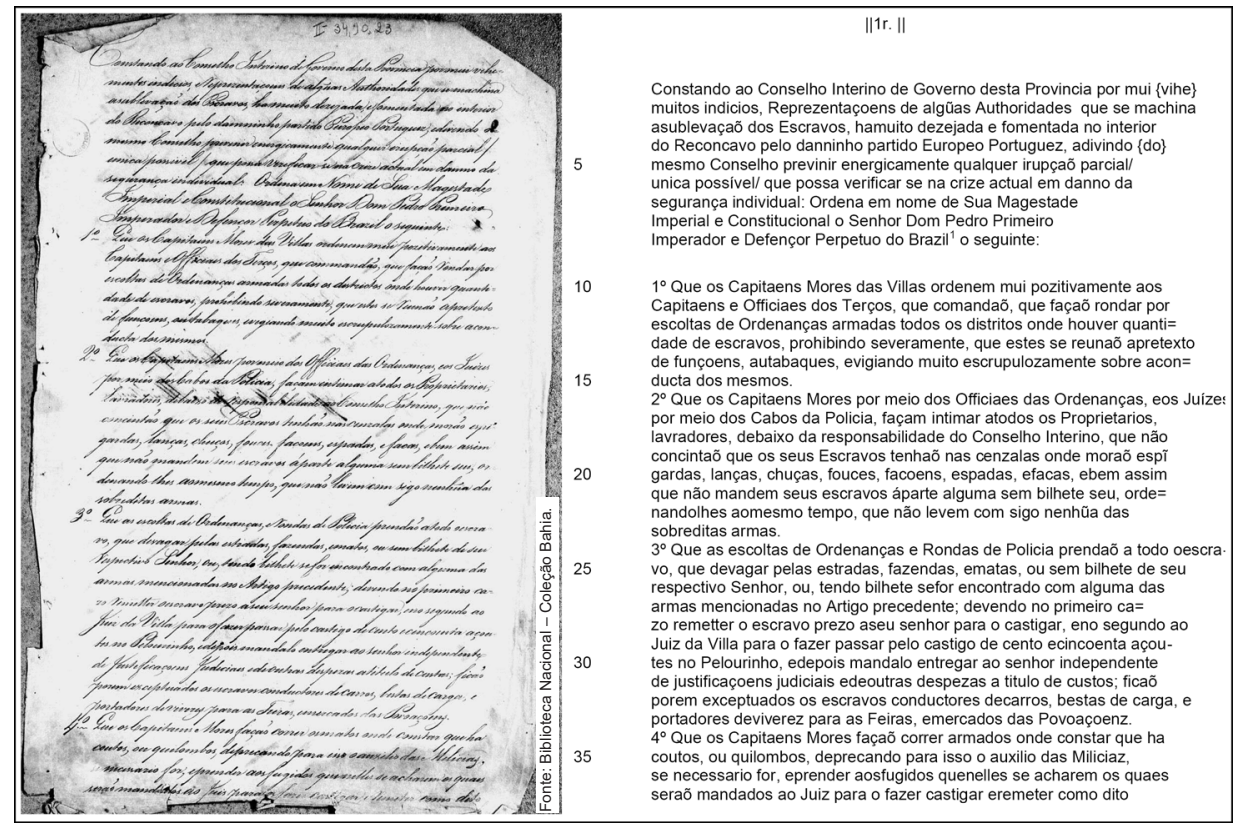

Fonte: GONÇALVES, 2018. 
Figura 2 - Fac-símile e edição semidiplomática da Resolução do Conselho Interino do Governo da Bahia - 28 de novembro de 1822 - Cachoeira - Bahia - f. 1 v

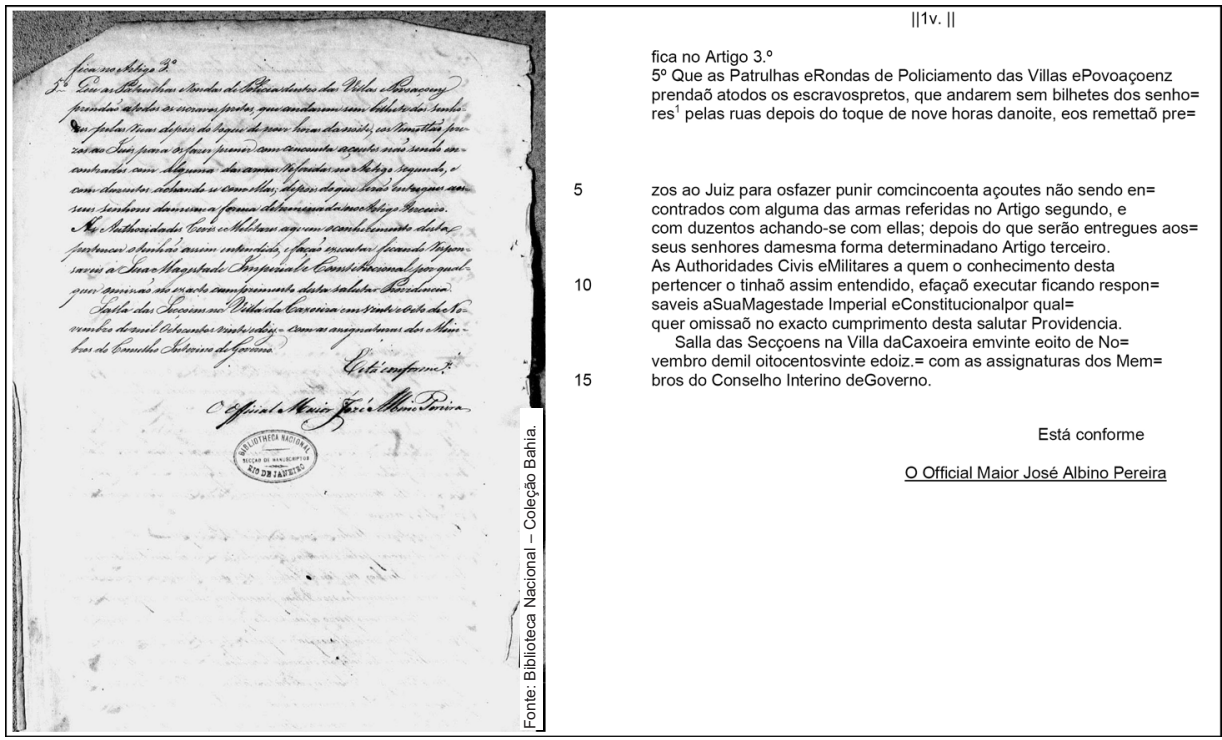

Fonte: GONÇALVES, 2018.

Com se verá adiante, o manuscrito, de teor políticosocial da administração pública, traz ao conhecimento de diversos públicos cenas do enunciador, da enunciação e dos contextos discursivos e históricos de poder, vigilância e resistência das revoltas escravas na Bahia. Além disso, os discursos analisados no texto permitem perceber quais as práticas sociopolíticas e culturais mobilizadas pelo governo do Império e da Província contra os movimentos contestatórios e revolucionários dos escravizados, com a adoção de vários posicionamentos de controle da região do Recôncavo baiano. Para tanto, esses textos apresentam contribuições significativas para a construção de um ethos discursivo-ideológico do poder institucional, imperialista e provincial, compondo o discurso da administração, no qual se identificam as tensões, os conflitos e os enfrentamentos nacionais de um opositor concreto.

\section{O ethos e a cena de enunciação: aporte teórico-metodológico}

O ethos pode ser considerado um caminho para a leitura, a análise e a interpretação do discurso de caráter administrativo que circulou no Brasil oitocentista. Segundo Maingueneau (2008, p.220), o conceito de ethos é retomado dos manuscritos de retórica e "designa a imagem de si que o locutor constrói em seu discurso para exercer uma influência sobre seu alocutário". Como pode ser aferido, esse conceito tem vinculações com o enunciador e a sua relação de conquista com o público.
No campo argumentativo, o ethos era responsável por mediar à conjuntura efetiva de um dado discurso institucional, emitindo os discursos oficiais, por meio de registros manuscritos, com algumas ordens que exigem garantias, entre as quais "comunicar as ocorrências locais" e "demonstrar submissão pessoal e, com isso, exaltar a personalidade de seus superiores na hierarquia do governo [...] de que era funcionário" (MUNHOZ, 2017, p. 141).

Considerando-se o texto histórico, o ethos discursivo tematiza a violência institucional em contextos políticosociais de revoltas de escravos, podendo se observar como o sujeito enunciador se articula com o outro e com outros discursos, a partir da imagem que ele constrói de si, no discurso e no seu posicionamento sociopolítico. Outro aspecto importante do ethos é o ethos prévio, considerado como "a imagem que o auditório faz do locutor no momento em que este toma a palavra" (AMOSSY, 2005 , p. 25). Nesse viés interativo, o ethos discursivo é um momento, um olhar sobre a cena, incorporando o leitor a um universo que evoca aspectos político-sociais da Bahia.

No texto, os discursos políticos das instâncias institucionais entram em conflito com o discurso dos nossos heróis negros, e, portanto, serão articulados para agirem "um sobre o outro", em um jogo de intimidação e repressão (CHARAUDEAU, 2006). A partir do excerto, pode-se observar que o sujeito enunciador apresenta informações sobre os movimentos insurgentes e as punições e perseguições resultantes dessa vigilância: 
$4^{\circ}$ Que os Capitães- Mores façam correr armados onde constar que há/ coutos, ou quilombos, deprecando para isso o auxilio das Milícias/ se necessário for, e prender aos fugidos que nelles se acharem os quais/ seraõ mandados ao Juiz para o fazer castigar e remeter como dito/ fica no Artigo $3^{\circ}$ (RESOLUÇÃO, 1822, f 1r, 1. 34-37; f.1v, 1. 1).

Como se pode perceber, no contexto institucional registrado na Resolução observa-se uma imagem negativa das revoltas na Bahia, criada pelo poder institucional do Império e da Província, através do texto burocrático-administrativo emitido pela Secretaria do Governo da Província da Bahia. Busca-se desqualificar e deslegitimar os movimentos dos escravos insurgentes, como subversivos, recorrendo-se a vários "procedimentos discursivos" (MAINGUENEAU, 2006, p. 92), afirmados em excertos como "[...] há/muitos indícios, representações de algumas Autoridades, que se machina/a sublevação de escravos" (f. 1, 1. 1-3), que inclusive contou com o apoio do partido europeu português.

Maingueneau (2008) mobiliza a noção de ethos no quadro da análise do discurso e, sendo uma noção que se constrói através do discurso, o ethos se constitui em um processo interativo do exercício da palavra e de influência sobre o outro. Ainda para Maingueneau (2008, p. 17), o ethos

é uma noção fundamentalmente híbrida (sóciodiscursiva), um comportamento socialmente avaliado, que não pode ser apreendido fora de uma situação de comunicação precisa, integrada ela mesma numa determinada conjuntura sócio-histórica.

Portanto, a voz do enunciador se vincula a um corpo enunciado historicamente e apresentado "em termos de um processo enunciativo, em que determinados sujeitos são levados a se inserirem em uma determinada posição discursiva", constituída em "instância subjetiva que se manifesta por meio do discurso" (ANDRADE; SANTIAGO-ALMEIDA; BARONAS, 2014, p. 401).

Por outro lado, o ethos se relaciona de fato aos conceitos morais e políticos que o enunciador produz no discurso na cena social e política que ele ocupa, atribuindo a ele a autoridade, a credibilidade daquilo que é dito e possibilitando ao intérprete/leitor à incorporação do ethos, pois "o enunciação da obra confere uma "corporalidade" ao fiador. Ela lhe dá corpo", acionando esquemas que remetem "a uma maneira específica de se remeter ao mundo habitando seu próprio corpo" e a "constituição de um corpo" (MANGUENEAU, 2008a, p. 18) dos que se filiam ao discurso do enunciador. Acrescendo-se ao tom, ao caráter e à corporalidade, o ethos pressupõe um "comportamento socialmente avaliado" no âmbito da comunicação "[...] uma forma de mover-se no espaço social, uma disciplina tácita do corpo, apreendida por meio de um comportamento" (MAINGUENEAU, 2006, p. 60, 62).

É importante também reconhecer o ethos escritural, com as suas duas faces, o ethos prévio, que se vincula à imagem apresentada pelo orador na sua cena social, a partir do conhecimento antecipado que os sujeitos tem das representações e das enunciações anteriores apresentadas pelo orador, antes da interação verbal; e o ethos discursivo, mais vinculado à imagem que o orador constrói de si mesmo no decorrer do evento enunciativo (MAINGUENEAU, 2008b; MENDES, 2014).

\section{Construção discursiva do ethos da autoridade institucional}

Para enfatizar o ato discursivo vinculado à dominação humana, que registra a decisão, a ordem da autoridade imperial de Sua Magestade Imperial e Constitucional, o Senhor Dom Pedro Primeiro, o Oficial Maior da Secretaria de Governo da Província da Bahia, José Albino Pereira enuncia no documento a ordem que deriva de uma demanda social e política, na tentativa de conter uma sublevação de escravos em Cachoeira - Bahia.

Assim, no que tange às práticas políticas e administrativas adotadas pelo Regime Imperial Português, em relação ao desenvolvimento da província, destaca-se o "prevenir energicamente qualquer irrupção parcial/única possível, que possa verificar se na crise atual [culmine] em dano da /segurança individual" (f. 1r, 1. 5-7). Esse ato é fundado na própria atribuição conferida ao Oficial José Albino Pereira e na função que ele ocupa como representante institucional. Dessa forma, o destinatário do discurso se identifica com a ameaça à paz e à segurança do corpo social, pois, para Mangueneau,

O poder de persuasão de um discurso deve-se, em parte, ao fato de ele constranger o destinatário a se identificar com o movimento de um corpo, seja ele esquemático ou investido de valores historicamente especificados. Com isso, também tomamos distância de uma concepção do discurso que se faz ver em noções como "procedimento" ou "estratégia", para a qual os conteúdos seriam independentes da cena de enunciação que deles se encarregam. Afinal, cremos que a adesão do destinatário se opera por um escoramento recíproco entre a cena de enunciação, da qual o ethos participa, e o conteúdo nela desdobrado (MANGUENEAU, 2008a, p. 29).

Nesse caminho, José Albino Ferreira foi designado como Oficial Maior, para realizar a produção documental da província, apresentando, portanto, a habilidade de escrita e de conhecimento de diretrizes diplomáticas na elaboração de documentos que registravam os discursos 
políticos oficiais do Império e da Província, por ter escrito outros documentos oficiais.

A Gazeta do Rio de Janeiro de 31 de janeiro de $1821^{3}$, uma publicação da Impressão Régia, propagadora de atos oficiais, registra uma "relação dos Despachos publicados na Corte pela Secretaria de Estado dos Negocios do Reino. Dia 22 de janeiro de 1821. Aniversario Natalicio da Serenissima Senhora Princesa Real do Reino Unido de Portugal, Brazil e Algarves", publicação na qual consta, entre os Cavaleiros da Ordem de Cristo, em remuneração de serviços, o nome do "Official Maior da Secretaria do Governo da Provincia da Bahia, José Albino Pereira" (GAZETA DO RIO DE JANEIRO, 31/11/1821, p. 1).

$\mathrm{Na}$ cenografia da repressão que se instaura, por exemplo, no toque de recolher, o ethos do conhecedor da vida administrativa e política da província sabe a importância dos ajuntamentos comunitários para os contextos subversivos, das rodas de música e dança dos escravos "proibindo severamente, que estes se reúnam a pretexto/ de funções, atabaques" (f 1r, 1. 13-14). Assim, apresenta-se "do ponto de vista do caráter [...] um fiador que deixa emergir diferentes discursos repressivos e punitivos"; e do "ponto de vista da corporalidade, emerge como fiador", um oficial da Secretaria do Governo, que reitera a posição de um representante de sua Magestade Imperial e Constitucional, atestando com o ato de escrever, "Está conforme" (f 1v, 1. 16). (DI FANTI, 2009)

Para Maingueneu (2008, p. 27), há um ethos em um enunciado histórico, político, jurídico e administrativo. No caso de textos históricos, administrativos ou jurídicos, por exemplo, os enunciadores "são além dos seres empíricos que produzem materialmente os textos", mas são entidades coletivas (os homens da lei, oficiais da Câmara), eles "mesmos representantes de entidades abstratas", como a lei, a administração colonial, "cujos membros estão autorizados a assumir o poder quando tomam a palavra".

Nesse viés, José Albino Pereira recorre aos recursos retóricos, que visam cumprir a ordem de Sua Majestade, que também desempenha um papel do poder institucional, assim embasado em um ethos "o coenunciador faz mais que decifrar conteúdos: ele participa do mundo configurado pela enunciação, ele acede a uma identidade de algum modo encarnada, permitindo ele próprio que um fiador encarne" (MAINGUENEAU, 2008, p. 29).

Por meio do exercício das palavras, das escolhas lexicais e da influência sobre o outro, faz-nos acreditar

\footnotetext{
3 A Gazeta do Rio de Janeiro, primeiro jornal redigido e publicado totalmente no Brasil pela Impressão Régia, foi lançada a 10 de setembro de 1808 , no Rio de Janeiro, como órgão oficial do governo português durante a permanência de D. João VI no Brasil. Todavia sua última publicação data de 31 de dezembro de 1822 - edição n. 157, devido a Independência. Cf. BND Digital [2015]. Disponível em: https://bndigital. bn.gov.br/artigos/gazeta-do-rio-de-janeiro-2/. Acesso em: 8 de abr. 2018.
}

que conter as revoltas escravas era uma questão de segurança nacional, com o fim de garantir e assegurar a ordem da Província e do Império. Assim, constrói-se na cena da enunciação um discurso firme, autoritário, vigilante e punitivo sobre a política do Império em relação aos movimentos contestatórios, pois as autoridades do Brasil, e, em particular, da Bahia se encontravam com algumas questões relevantes a serem resolvidas, entre as quais a necessidade da gestão do controle social da população negra no Brasil, com vistas à repressão às revoltas. São esses acontecimentos que motivam as ações administrativas e de ordem da Resolução de 1822, que se traduzem em ações discursivas e interventivas para a ameaça que representava os movimentos revoltosos, restringindo-se o trânsito dos escravizados da província da Bahia, com o fim de "evitar que estes africanos saíssem da província para qualquer outra parte do império" (BRITO, 2008, p. 46)

Essa atmosfera das revoltas, marcada pelas tensões políticas e propensas a todo tipo de ato contestatório, é materializada nos documentos oficiais da administração do século XIX, que registravam diferentes discursos de cunho político, produzidos e circulados na sociedade, com o fim de legitimar o poder das autoridades políticas europeias e locais. Esses fragmentos ostentam um léxico de vigilância e punição, em construções como "proibindo severamente", (f. 1r,s 1. 13); "vigiando muito escrupulosamente", (f. 1r, 1. 14), "façam intimidar" (f. 1r, 1. 17) e em unidades léxicas vinculadas a esferas e imagens bem definidas como nos verbos prender e castigar (f. 1r, 1. 24, 28, ), ativando um mundo sociopolítico que demanda medidas legais específicas por parte do governo do Império e da Província. O leitor é convidado a participar dos discursos de reconhecimento desse estado de vigilância em relação às revoltas escravas, mas também a compor o corpo de luta e resistência sociopolítica, buscando soluções para os seus contextos de enfrentamento e resistência.

No início, com o crescente temor diante dos riscos de revoltas, em outras cidades da Província da Bahia, já tinham sido tomadas medidas repressivas, visando o controle da população africana:

Naturalmente, o controle da população escrava aumentou após o ataque a Nazaré. O conde da Ponte adotou uma série de medidas para fazer frente ao que considerava excessiva liberalidade dos senhores com seus escravos. Providências típicas nesse sentido foram adotadas por um juiz de Maragogipe. A 31 de janeiro, o juiz de direito Joaquim Inácio da Costa ordenou que os escravos vivendo longe dos senhores no ganho retornassem a suas casas em 24 horas, sob pena de serem presos e açoitados. Os donos de casas e hospedarias que alugassem quartos a escravos seriam multados em 6 mil réis por cada inquilino ilegal. 
Foi estabelecido um toque de recolher para escravos circulando nas ruas sem passes assinados pelos senhores. Os batuques e danças, feitos de dia ou de noite, foram terminantemente proibidos. Finalmente, o juiz pediu autorização para que seus agentes atirassem para matar contra qualquer escravo suspeito que resistisse à ordem de prisão. Eram medidas típicas do tempo do conde da Ponte, mas seu governo estava chegando ao fim (REIS, 1992, p. 104).

O ethos da autoridade institucional em estudo reitera essa prática do toque de recolher para escravos. Observase que o próprio crescimento das notícias de sublevação dos escravos fez com que a polícia redobrasse a vigilância, com o fim de conter movimentos de revolta, antes que eles acontecessem. Nesse contexto, o discurso é também uma forma de dizer que constrói as duas faces dos sujeitos da enunciação de um lado o enunciador, mas também o seu correlato, o enunciatário. Essa construção da forma de dizer é observada na enunciação da vigência de medidas preventivas registradas em alguns artigos da Resolução (1822) editada:

$1^{\circ}$ Que os Capitães-Mores das Vilas ordenem mui positivamente aos/ Capitães e Oficiais dos Terços, que comandam, que façam rondar por/ escoltas de Ordenanças armadas todos os distritos onde houver quanti-/dade de escravos, proibindo severamente, que estes se reúnam a pretexto/ de funções, atabaques, e vigiando muito escrupulosamente sobre a con-/ duta dos mesmos (RESOLUÇÃO, 28.10.1822, f. 1 r, L. 10 -15 ; f. 1v, L. 2 -8)

Dialogando com Charaudeau e Maingueneau (2014, p.193), portanto "a enunciação [...] permite representar fatos no enunciado, mas, por outro, constitui por si mesma um fato, um acontecimento único definido no tempo e no espaço". Nesse contexto, a história política do discurso da repressão das instituições do Império e da Província contra a revolta de escravos perde o seu conceito clássico e tradicional de história das narrativas heroicas de um povo, embasadas pelo espaço, e passa a se constituir como espaço de memória (FALCON, 1997), considerando-se o ethos discursivo, o enunciador, o enunciatário, as cenas da enunciação e discutindo-se "a política e a sociedade na sua complexidade" (ARAS, 2012, p. 152).

Para tanto, podem ser observadas mobilizações discursivas da Província de Cachoeira na tentativa de assegurar o controle daquele território, impondo dinâmicas definidas de circulação na Província, contrariando os direitos individuais e coletivos, como o controle opressivo do direito de ir e vir dos sujeitos, por meio da prática do toque de recolher. Analisando a cena enunciativa do discurso institucional, observamos:

\begin{abstract}
$5^{\circ}$ Que as Patrulhas e Rondas de Polícia dentro das Vilas e Povoações prendam a todos os escravos pretos, que andarem sem bilhetes dos senho-/res pelas ruas depois do toque de nove horas da noite, e as remetam pre-/ sos ao Juiz para os fazer punir com cinquenta açoites não sendo em-/contrados com alguma das armas referidas no Artigo segundo, e //com duzentas achando-se com elas; depois do que serão entregue aos-/seus senhores da mesma forma determinada no Artigo terceiro (RESOLUÇÃO, 28.10.1822, f. $1 \mathrm{r}$, L. $10-15$; f. 1v, L. 2 -8).
\end{abstract}

Nesse contexto, ocorreram várias revoltas em 1822, em tempos que antecedem a produção discursiva da autoridade institucional. Portanto, ainda nesse período, registram-se várias ações discursivas e sociais de movimentos contestatórios e revolucionários, mesmo com a adoção de atos punitivos na tentativa de assegurar o controle do corpo social nessa região do Recôncavo. Foram proibidas reuniões, festas religiosas e mundanas, porte de arma por parte dos escravizados e a livre circulação deles fora das propriedades dos senhores (REIS, 1992). Essa postura é motivada por atos enunciativos de denúncias e de indícios de sublevação de escravizados apoiada pelos portugueses e "há muito desejada e fomentada no interior/ do Recôncavo pelo daninho partido Europeu Portugues advindo do/ mesmo Conselho prevenir energicamente qualquer irrupção parcial/” (RESOLUÇÃO, 28.11.1822, f. 1r, p. 3-5).

Vale ainda acrescentar que o ethe das autoridades institucionais vinculadas nos textos da legislação vigente no século XIX não assegurava os direitos civis aos escravizados, mas, por outro lado, em contextos de crimes, atribuía responsabilidade aos seus atos, julgando-os de acordo com as leis vigentes, "situação esdrúxula, que inseria o escravo na cidadania apenas quando criminoso" (ARAS, 2012, p. 167) Posteriormente, foram tomadas medidas para a construção de um plano repressivo para a região, por meio de policiamento do Recôncavo, com a finalidade de combater e julgar os escravizados insurgentes. Mas vale ressaltar que nem mesmo o aumento da presença militar e o reforço das tropas inibiram os escravizados, que continuaram a se rebelar, medida que não acaba completamente com as revoltas.

Assim a imagem dos sujeitos no discurso, imperial e provincial, é construída por meio do ethos discursivo da enunciação e a imagem do enunciador é legitimada pela incorporação do tom, do caráter e da corporalidade do seu outro, o enunciador, a autoridade institucional (MAINGUENEAU, 2005).

Desse modo, foi relevante refletir e avaliar como a legislação provincial da Bahia demandava atos e ações discursivas de controle social e político sobre os 
escravizados insurgentes, no início do século XIX, por meio dos presidentes e dos chefes de polícia da província (BRITO, 2008), através da edição e do estudo de Resoluções expedidas nesse período.

\section{Considerações finais}

O estudo do ethos discursivo da autoridade institucional, a partir da edição do texto da Resolução de 28 de novembro de 1822 , registra que o ethos deixa marcas linguísticas e textuais na materialidade discursiva, que nos possibilita interagir com a imagem do enunciador através das pistas que são registradas no texto, entre os quais o contexto, os sujeitos envolvidos, o ethos prévio do Oficial José Albino Pereira e as características do gênero, Resolução, podendo se entrever ações políticas contrárias, que não legitimam as ordens de repressão narradas no texto.

Por outro lado, escravizados insurgentes deixaram nos registros jurídicos do século XIX, por meio de leis, ações e debates políticos, os vestígios dos discursos da sua luta e resistência, visto que eles representavam, no contexto institucional e político dos senhores de escravos, um problema de segurança, que demandava medidas legais específicas por parte do governo do Império e da Província, como forma de repressão. Portanto, ao se analisar o ethos discursivo, observa-se que os segmentos sociais de prestígio temiam os riscos ao seu modo de vida, fato que fragiliza a estrutura social escravista.

Dessa forma, a práxis discursivo-filológica leva em consideração diversos modelos editoriais, assentando-se em consistentes reflexões sobre a subjetivação, que permeiam a produção, a circulação e a recepção dos discursos conflituosos, na relação dialética entre identidade e alteridade. Nesse contexto, as abordagens discursivas articuladas com as abordagens filológicas cumprem um papel histórico e político, à medida que trazem à reflexão, de diversos públicos, outras nuances interpretativas de documentos manuscritos históricos de teor político-social da administração pública brasileira, que legitimam a relevância dos enfrentamentos e da resistência, em contextos de vigilância.

Essas fontes textuais manuscritas de gêneros diversificados fazem parte de um patrimônio cultural comum, expressando contextos discursivos da organização político-administrativa, da administração eclesiástica, militar e judicial da colônia, facilitando a interpretação dos dispositivos de instrumentos legais e diplomáticos que regulavam ou não o cotidiano da Bahia oitocentista.

\section{Referências}

AMOSSY, R. Da noção retórica de ethos à análise do discurso. In: AMOSSY, Ruth. Imagens de si no discurso: a construção do ethos. São Paulo: Contexto, 2005. https://doi. org/10.35501/dissol.v0i8.485

AMOSSY, R. L'argumentation dans le discours. 3. éd. Paris: Armand Colin, 2010.

ANDRADE, E.; SANTIAGO-ALMEIDA, M.; BARONAS, R. Plano de guerra da Capitania de Matto Grosso: janeiro de 1800. 2. ed. reimpr. e revisada. Cuiabá: EDUFMT, 2014.

ARAS, L. M.B. de. Escravos nos movimentos federalistas. Bahia, 1832-1833. Politeia: História e Sociedade, [S. l.], v. 2, n. 1, p. 151-172, 2012. Disponível em: http://www.snh2011. anpuh.org/resources/anais/14/1299165598_ARQUIVO_Aside iasfederalistasnaBahiaoitocentista(LinaAras).pdf. Acesso em: 1 mar. 2018.

BELLOTTO, Heloísa. Como fazer análise diplomática e análise tipológica de documento de arquivo. São Paulo: Arquivo do Estado e Imprensa Oficial do Estado, 2002. (Série Como Fazer, Vol. 8). https://doi.org/10.26512/2016. 03.d. 20288

BRITO, L. C. Só o rigor da lei: os africanos e a legislação baiana do século XIX. Sankofa, Revista de História da África e de Estudos da Diáspora Africana, [S. l.], v. 1, n. 2, p. 30 - 57, 2008. https://doi.org/10.11606/issn.1983-6023. sank.2008.88729

CAMBRAIA, Cesar Nardelli; CUNHA, Antonio Geraldo da; MEGALE, Heitor. Normas para a transcrição de documentos manuscritos para a história do português do Brasil. In: A carta de Pero Vaz de Caminha. São Paulo: Humanitas, 1999. p. 23-26. (Série Série Diachronica, Vol. 1). https://doi.org/ 10.11606/issn.2595-2501.rusp.1950.143235

CHARADEAU, Patrick. Discurso politico. São Paulo: Contexto, 2006.

ChaRAUDEAU, P.; MAINGUENEAU, D. Dicionário de análise do discurso. São Paulo: Contexto, 2014.

DANTAS, Mônica. Revoltas, motins, revoluções: homens livres pobres e libertos no Brasil do século XIX. São Paulo: Alameda; 2011. https://doi.org/10.3368/lbr.53.2.e31

DE FANTI, Maria da Glória Corrêa. Identidade, alteridade e cultura regional: a construção do ethos milongueiro gaúcho. Alfa, São Paulo, v. 53, n. 1, p. 149-166, 2009.

FALCON, F. História e Poder. In: CARDOSO, C. F.; VAINFAS, R. (org.). Domínios da História. Rio de Janeiro: Campus, 1997. p.61-90.

GAZETA DO RIO DE JANEIRO. 31.01.1821; v. 9, n. 1. Disponível em: http://objdigital.bn.br/acervo_digital/div periodicos/gazeta_rj/gazeta_rj_1821/gazeta_rj_1821_009.pdf. Acesso em: 5 abr. 2018. https://doi.org/10.15603/2175-7755/ cs.v29n49p27-41 
GONÇALVES, Eliana Correia Brandão. Léxico e história: lutas e contextos de violência em documentos da Capitania da Bahia. Revista da ABRALIN, Curitiba, v. 16, n. 2, p. 191-218, abr. 2017. ISSN 0102-7158. Disponível em: https://revistas. ufpr.br/abralin/article/view/52006/32046. Acesso em: 14 ago. 2019. https://doi.org/10.5380/rabl.v16i2.52006

GONÇALVES, Eliana Correia Brandão. Leitura críticofilológica de Resolução de 1822: revoltas, vigilância, violência e punição na Bahia do século XIX. Revista Filologia e Linguística Portuguesa, São Paulo, v. 20, n. 2, p. 153-174, ago./dez. 2018. https://doi.org/10.11606/issn.2176-9419. v20i2p153-174

HABIB, Paulo Paulinelli. O ethos na argumentação: análise discursiva de uma carta- protesto de Sobral Pinto ao Presidente Costa e Silva. 2008, 183 f. Dissertação (Mestrado e Letras) - Universidade Federal de Minas Gerais, Faculdades de Letras, Minas Gerais, 2008. https://doi.org/10.5327/z2447211520191800064

MAINGUENEAU, D. Ethos discursivo. 2. ed. São Paulo, SP: Contexto, 2011.

MAINGUENEAU, D. A noção de ethos discursivo. In: MOTTA, A. R.; SALGADO, L. Ethos discursivo. São Paulo: Contexto, 2008a. p. 11-32.

MAINGUENEAU, D. Análise de textos de comunicação. 3. ed. Tradução Cecília P. de Souza-e-Silva e Décio Rocha. São Paulo: Cortez, 2005c. https://doi.org/10.18309/anp. v1i12.518

MAINGUENEAU, D. Cenas da enunciação. Org. Sírio Possenti e Maria Cecília Pérez de Souza-e-Silva. São Paulo, SP: Parábola Editorial, 2008b.

MAINGUENEAU, D. Ethos, cenografia, incorporação. In: AMOSSY, R. (org.). Imagens de si no discurso: a construção do ethos. Tradução Dílson Ferreira da Cruz, Fabiana Komesu e Sírio Possenti. São Paulo: Contexto, 2005a. p. 69-92. https:// doi.org/10.26512/les.v10i2.9291

MAINGUENEAU, Dominique. A propósito do ethos. In: MOTTA, Ana Raquel; SALGADO, Luciana (org.). Ethos discursivo. São Paulo: Contexto, 2008c. p. 11-29.

MAINGUENEAU, Dominique. Gênese dos discursos. Tradução Sírio Possenti. Curitiba: Criar, 2005b.

MENDES, Mírian Lúcia Brandão. A retórica escravista: as emoções no discurso das cartas de Alencar a favor da escravidão. EID\&A - Revista Eletrônica de Estudos Integrados em Discurso e Argumentação, Ilhéus, n. 7, p. 183-194, dez. 2014. https://doi.org/10.17648/eidea$18-2197$

MUNHOZ, Renata Ferreira. O poder do discurso de submissão: reflexões sobre as práticas discursivas na esfera da administração setecentista. Redis: Revista de Estudos do Discurso, n. 6, p. 140-171, 2017. https://doi. org/10.21747/21833958/red6a6
REIS, João José. Recôncavo rebelde: revoltas de escravos nos engenhos bahianos. Afroásia, Salvador, n. 15, p. 100-126, 1992.

Recebido em: 1/6/2018.

Aprovado em: 8/10/2019.

Publicado em: 21/12/2019.

Autora:

Eliana Correia Brandẽo Gonçalves

Doutora, professora da Universidade Federal da Bahia, Salvador, BA, Brasil.

Orcid: https://orcid.org/0000-0003-1064-5382

E-mail: elianabrand7@gmail.com

Endereço: Av. Adhemar de Barros, s/n - Ondina

40170-110, Salvador, BA, Brasil 